\title{
Chronic Thromboembolic Pulmonary Hypertension Due to Popliteal Vein Aneurysm
}

This article was published in the following Dove Press journal:

International Medical Case Reports Journal

\author{
Masakazu Tsubono ${ }^{1,2}$ \\ Kazuhiro Shimizu $\mathbb{D}^{2}$ \\ Shuji Sato $\mathbb{( D}^{2}$ \\ Takuro Ito ${ }^{2}$ \\ Takanori Ikeda' \\ 'Department of Internal Medicine, Toho \\ University Omori Medical Center, Tokyo, \\ Japan; ${ }^{2}$ Department of Internal Medicine, \\ Toho University Sakura Medical Center, \\ Chiba, Japan
}

Background: Venous thromboembolism (VTE) may present acutely as pulmonary embolism (PE), and its late complications include chronic thromboembolic pulmonary hypertension (CTEPH). PEs may arise from thrombi originating in a venous aneurysm, in rare cases of the popliteal vein.

Case Presentation: A 77-year-old woman was referred to our hospital due to respiratory distress. Computed tomography revealed pulmonary thrombi and a thrombus in a popliteal vein aneurysm (PVA); PE was diagnosed. After 3 months of anticoagulant therapy (rivaroxaban), her pulmonary hypertension showed little improvement. She underwent perfusion scintigraphy, which showed multiple perfusion defects, and Swan-Ganz catheterization. Mean pulmonary artery pressure was $26 \mathrm{mmHg}$. Pulmonary angiography revealed organized distal thrombi. Based on these findings, we diagnosed CTEPH due to recurrent formation of thrombi in the PVA.

Conclusion: Asymptomatic PVA can lead silently to PE and CTEPH. The possibility of asymptomatic recurrent VTE should be considered in patients with pulmonary hypertension and PVA.

Keywords: chronic thromboembolic pulmonary hypertension, popliteal vein aneurysm, pulmonary embolism, pulmonary hypertension, venous thromboembolism

\section{Introduction}

Venous thromboembolism (VTE), manifesting as deep vein thrombosis (DVT) or pulmonary embolism (PE), is encountered in various clinical situations. It may present acutely as PE, which is potentially fatal, and its late complications include post-thrombotic syndrome and chronic thromboembolic pulmonary hypertension $(\mathrm{CTEPH}) .{ }^{1}$ Although only a small proportion $(<4 \%)$ of patients with acute PE develop CTEPH, ${ }^{2,3}$ CTEPH is strongly associated with a history of VTE (PE and DVT in $75 \%$ and $56 \%$ of 679 patients whose data were included in an international prospective registry). ${ }^{4}$

Pulmonary embolism may arise from thrombi originating in a venous aneurysm (fusiform dilatation of a vein to at least twice its normal size). Large aneurysms carry an $80 \%$ risk of PE, even in cases in which anticoagulant therapy is given. ${ }^{5}$ Rarely, aneurysms develop in the popliteal vein. The causes of popliteal venous aneurysm (PVA) are unknown; however, congenital vein wall weakness, inflammation, and infection have been suggested as risk factors. ${ }^{6}$
Correspondence: Kazuhiro Shimizu

Department of Internal Medicine, Sakura Medical Center, School of Medicine, Toho University, 56I-4 Shimoshizu, Sakura City, Chiba, 285-874I, Japan

Tel $+8|-43-462-88| I$

Fax +8I-43-462-8820

Email k432@sakura.med.toho-u.ac.jp 


\section{A Before treatment in acute phase}
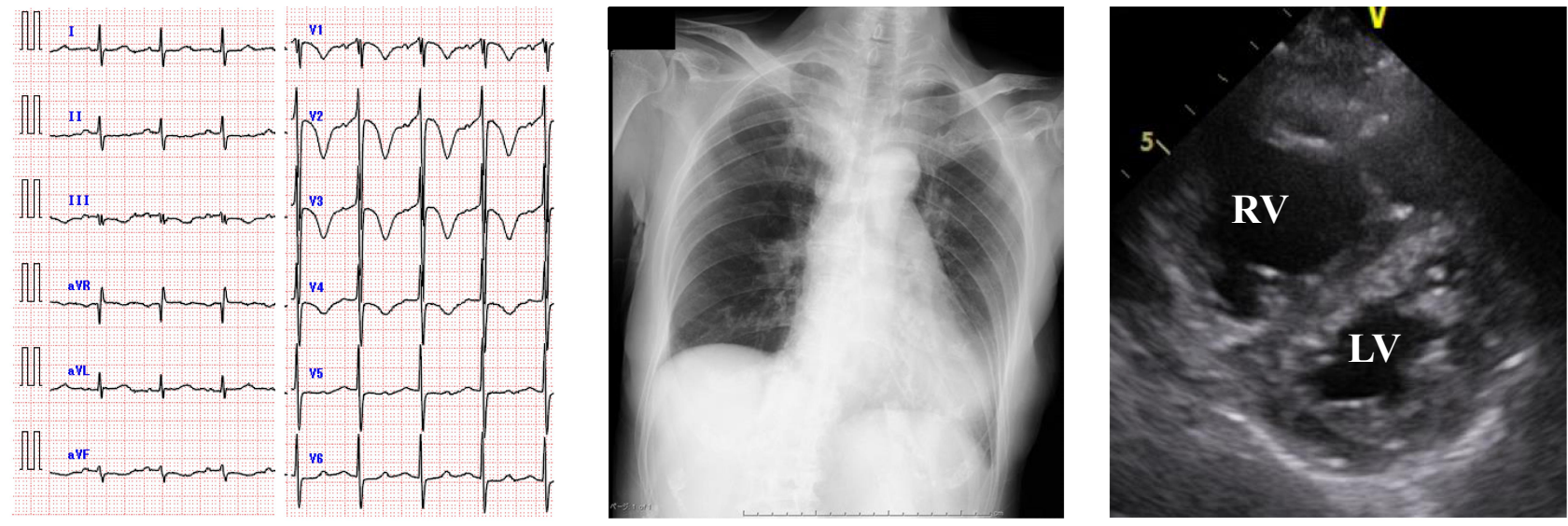

\section{B 12 weeks anticoagulant therapy}
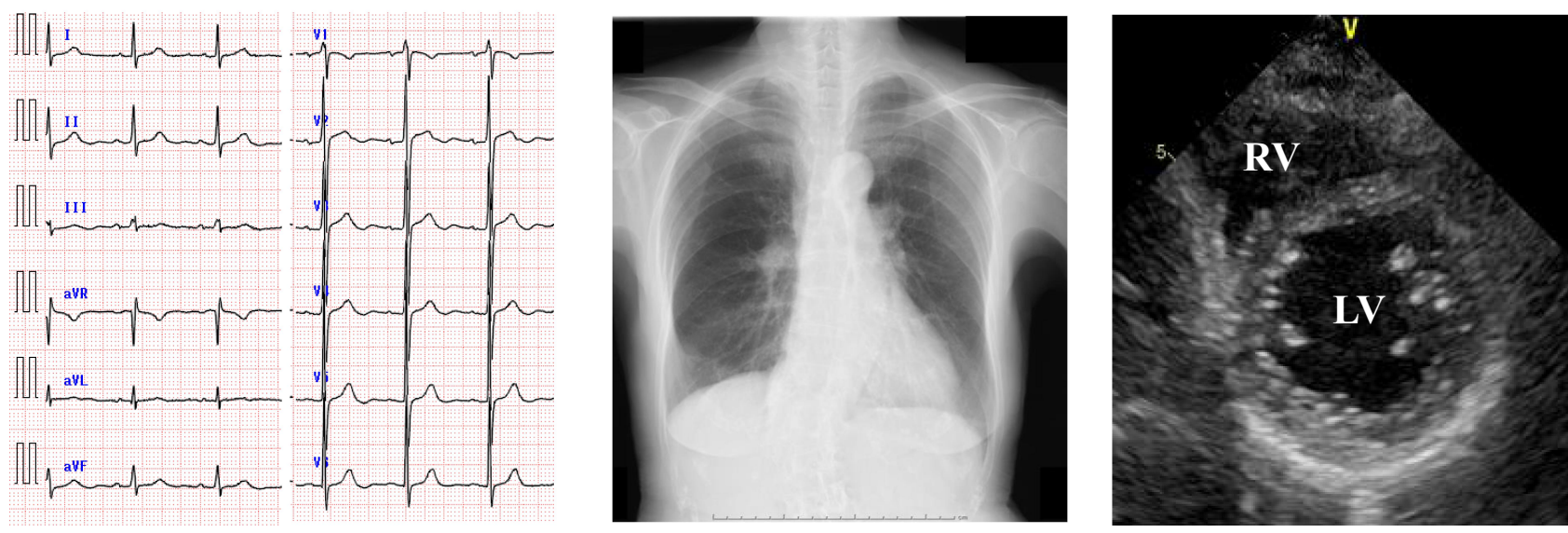

Figure I Electrocardiography, chest X-Ray, and echocardiography before and after 12 weeks anticoagulant therapy (A and B). Abbreviations: RV, right ventricle; LV, left ventricle.

Here, we describe a case of CTEPH due to asymptomatic PVA. To our knowledge, this is the first report of its kind.

\section{Case Presentation}

A woman aged 77 years was referred to our hospital due to respiratory distress. She had no medical history until then like hypertension, dyslipidemia or diabetes. And she also did not have any risk factors like thrombophilia, history of trauma, hospitalization steroids use, hormonal contraceptives, current smoking, chronic respiratory disease, infection, recent surgery, cancer and chemotherapy. Her blood pressure was $132 / 74 \mathrm{mmHg}$, she had a regular heart rate of 108 bpm and a respiratory rate of 18 breaths $/ \mathrm{min}$, and her oxygen saturation was $85 \%$ on room air.
Electrocardiography showed inverted $\mathrm{T}$ waves in leads V1-3. Chest X-ray showed dilatation of the pulmonary artery and a cardiothoracic ratio of $60 \%$ (Figure 1).

Echocardiography showed right ventricular dilatation and a tricuspid regurgitation pressure gradient of 70 mmHg (Figure 1). Computed tomography (CT) revealed thrombotic occlusions of both pulmonary arteries and, coincidentally, a thrombus in an aneurysm in the popliteal vein of the left leg (Figures 2 and 3). Right to left ventricle (RV:LV) diameter ratio, measured on the fourchamber view, was high (2.11). Based on these findings, acute PE was diagnosed and the patient was started on rivaroxaban $(15 \mathrm{mg}$ orally twice daily for the first 21 days, followed by a maintenance dose of $20 \mathrm{mg}$ orally once daily). 


\section{A Before treatment in acute phase}
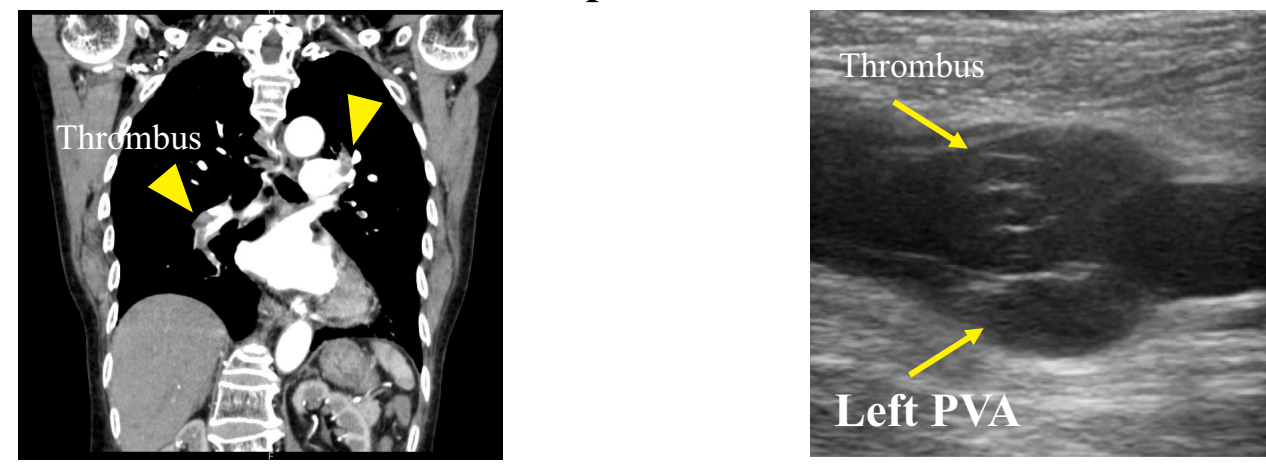

\section{B 12 weeks anticoagulant therapy}
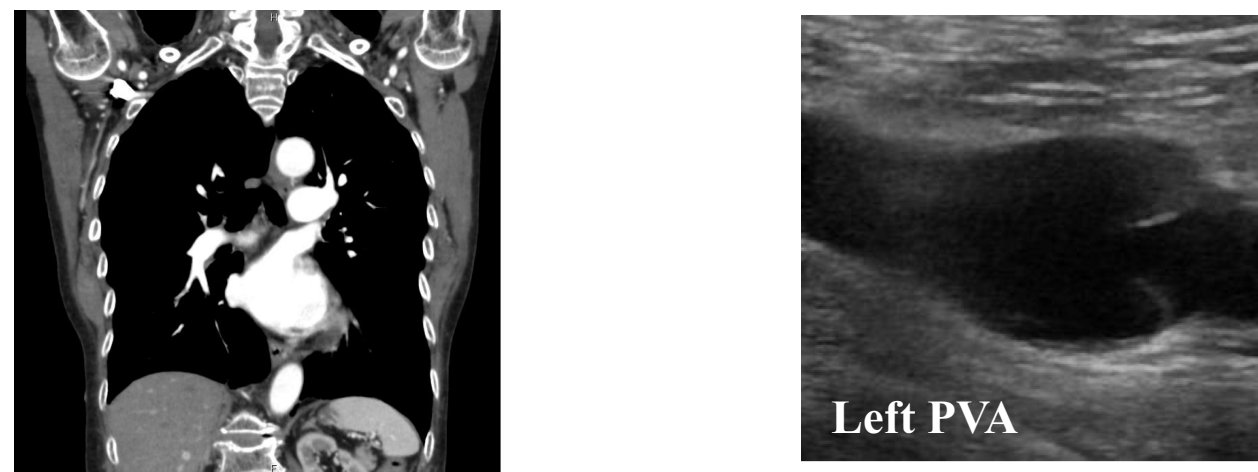

Figure 2 Thrombotic occlusion of pulmonary arteries and thrombus in the popliteal vein at first time and after 12 weeks anticoagulant therapy (A and B). Yellow arrows showed thrombus in pulmonary artery on computed tomography and showed thrombus in PVA on ultrasonography.

Abbreviation: PVA, popliteal vein aneurysm.

After 12 weeks of anticoagulant therapy, the thrombus in the popliteal vein aneurysm was disappeared (Figure 2). The D-dimer value had normalized (from $14.6 \mu \mathrm{g} / \mathrm{mL}$ to $0.5 \mu \mathrm{g} / \mathrm{mL}$ ). CT angiography showed dissipation of the pulmonary thrombus, but RV:LV diameter ratio remained high (1.25). Perfusion scintigraphy showed that multiple perfusion defects remained (Figures 3 and 4). SwanGanz catheterization was also performed. Mean pulmonary artery pressure was $26 \mathrm{mmHg}$, and pulmonary vascular resistance, 6.65 Wood units. Pulmonary angiography revealed organized distal thrombi. Based on these findings, we diagnosed CTEPH due to recurrent formation of thrombi in the PVA.

The patient is now due to undergo balloon pulmonary angioplasty (BPA) and surgery to treat the CTEPH and PVA, respectively.

\section{Discussion}

Standard medical treatment for CTEPH comprises anticoagulant therapy supplemented by diuretics and oxygen, as necessary. The guidelines of the European Society of Cardiology recommend anticoagulant therapy with a vitamin $\mathrm{K}$ antagonist (VKA). ${ }^{7}$ In cases in which the VKA fails to control $\mathrm{CTEPH}$, and the potential benefits are judged to outweigh the risks, the patient can be switched to a DOAC. ${ }^{8}$ The preference for a VKA over a direct oral anticoagulant (DOAC) for treating CTEPH is based on decades of clinical experience with the former compared with limited experience with the latter.

In the case described here, the patient was initially started on a DOAC, rivaroxaban, to treat her acute PE. Several months later, when CTEPH had been diagnosed, we decided to continue anticoagulant therapy 


\section{A Before treatment in acute phase}
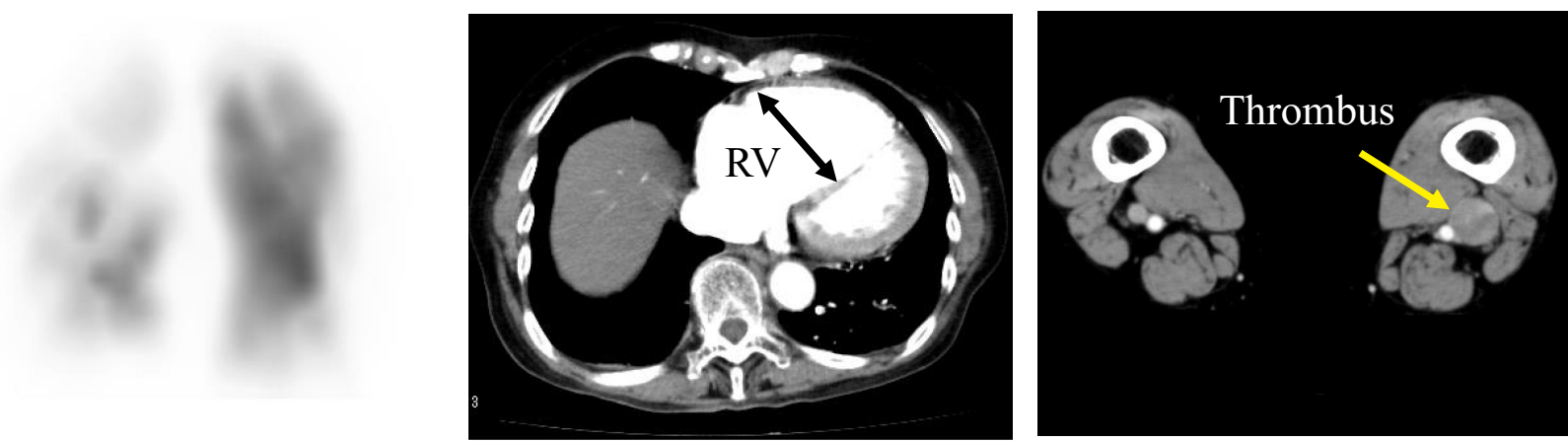

\section{B 12 weeks anticoagulant therapy}
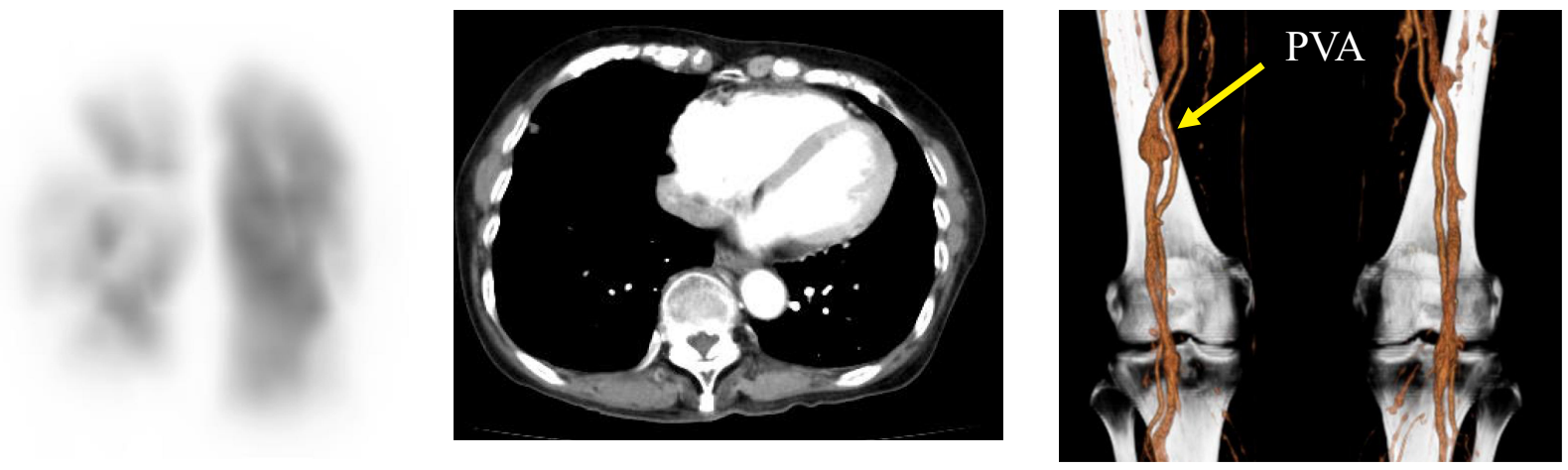

Figure 3 Perfusion scintigraphy, computed tomography, and CT angiography before and after 12 weeks anticoagulant therapy (A and B). Black arrow showed right ventricular dilatation. Yellow arrows showed thrombus (A) and popliteal vein aneurysm (B).

Abbreviations: RV, right ventricle; PVA, popliteal vein aneurysm.

with rivaroxaban rather than change it to a VKA, because the patient's clinical course was considered stable. Standard treatment for acute venous thromboembolism is limited by the need for parenteral heparin initially, with overlapping administration of a vitamin $\mathrm{K}$ antagonist. The relative efficacy and safety of rivaroxaban were similar to those of standard therapy in EINSTEIN program. ${ }^{9}$ So, we selected the rivaroxaban therapy in this case. But the efficacy of rivaroxaban therapy in $\mathrm{CTEPH}$ remains unclear. So, we decided to change standard therapy before BPA.

Evidence for DOAC has not yet been established in the CTEPH treatment. Now, powered multicenter prospective cohort studies with systematic, multimodality follow-up programs are needed to confirm the using DOAC for CTEPH. In this case, we might have better to change the standard VKA treatment earlier.

This case is an example of recurrent formation of thrombi in an asymptomatic PVA leading silently to PE and CTEPH. ${ }^{10}$ PVA is associated with a significant risk of fatal PE. ${ }^{2}$ In cases of CTEPH, timely therapeutic intervention greatly improves prognosis. ${ }^{11,12}$ Popliteal vein aneurysms $>20 \mathrm{~mm}$ should be considered for surgical treatment or lifelong anticoagulation, depending on the patient's preference. In this case, we planned surgery for resection of the popliteal vein aneurysm. ${ }^{13}$ The possibility of asymptomatic recurrent venous 


\section{Perfusion scintigraphy}

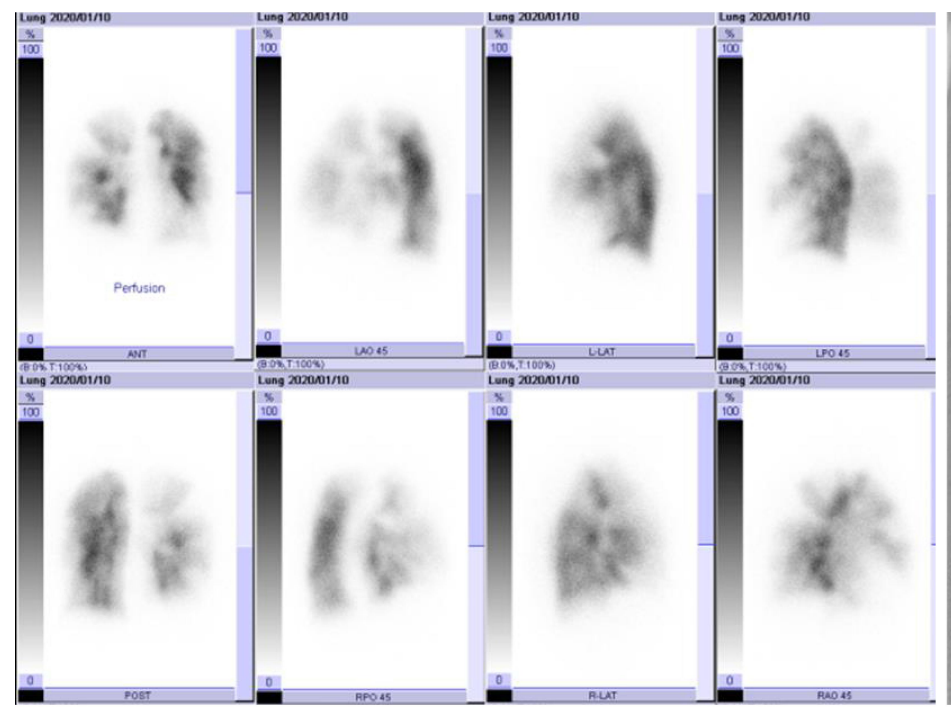

\section{Pulmonary angiography}

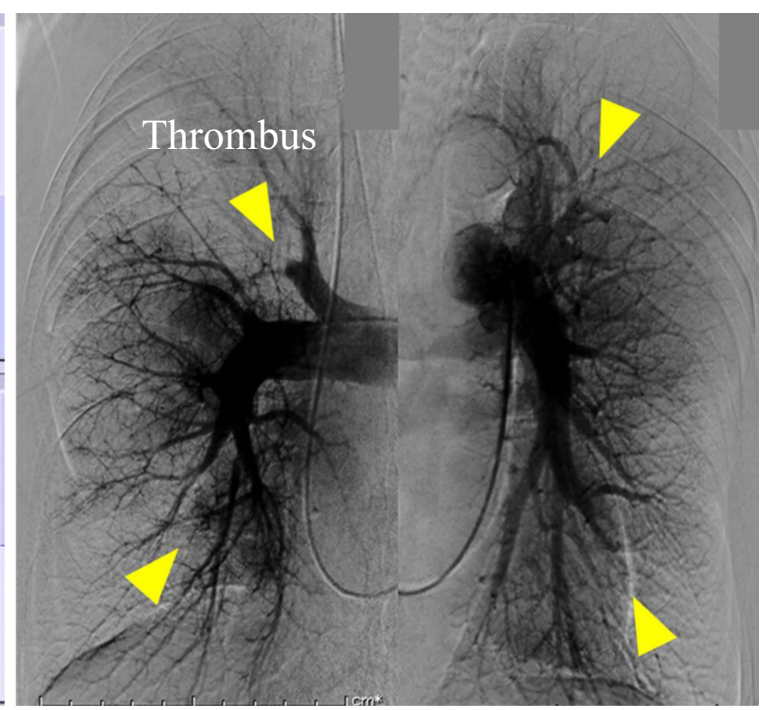

\section{2 weeks anticoagulant therapy}

Figure 4 Perfusion scintigraphy and pulmonary angiography after 12 weeks anticoagulant therapy. Chronic thrombus showed the perfusion defect on scintigraphy and pulmonary angiography. Yellow arrows showed the multiple chronic and organized thromboembolic obstructions in the distal part of the pulmonary arteries.

thromboembolism should be considered in patients with pulmonary hypertension and PVA.

\section{Ethical Approval}

The patient was treated in accordance with the ethical standards of institutional and national committees on human experimentation and with the Declaration of Helsinki (1975, and subsequent revisions). According to the guidelines of the Ethics Committee of Toho University School of Medicine (September 18, 2018), institutional approval was not required to publish the case details.

\section{Informed Consent}

The patient provided written informed consent for publication of the details of her case and the images shown in the figure.

\section{Acknowledgments}

We thank our colleagues in the Department of Cardiology, Toho University Medical Center, Sakura Hospital.

\section{Author Contributions}

All authors made substantial contributions to conception and design, acquisition of data, or analysis and interpretation of data; took part in drafting the article or revising it critically for important intellectual content; agreed to submit to the current journal; gave final approval of the version to be published; and agree to be accountable for all aspects of the work.

\section{Disclosure}

The authors declare that there is no conflict of interest.

\section{References}

1. Shimizu K, Iiduka T, Sato $\mathrm{S}$, et al. The clinical course of symptomatic deep vein thrombosis after 3 months of anticoagulant therapy using fondaparinux/edoxaban or fondaparinux/vitamin K antagonist. Ther Clin Risk Manag. 2018;14:377-383. doi:10.2147/TCRM. S153517

2. Park JS, Kim SD, Park IY, Lee DS, Kim W, Won JM. Popliteal vein aneurysm as a source of pulmonary embolism: report of a case and review of the world literature. Ann Vasc Surg. 2011;25(8):1139.e91139.e12. doi:10.1016/j.avsg.2011.02.045

3. Pengo V, Lensing AWA, Prins MH, For the Thromboembolic Pulmonary Hypertension Study Group, et al.. Incidence of chronic thromboembolic pulmonary hypertension after pulmonary embolism. N Engl J Med. 2004;350(22):2257-2264. doi:10.1056/NEJMoa032274

4. Pepke-Zaba J, Delcroix M, Lang I, et al. Chronic thromboembolic pulmonary hypertension (CTEPH): results from an international prospective registry. Circulation. 2011;124(18):1973-1981. doi:10.1161/ CIRCULATIONAHA.110.015008 
5. Sessa C, Nicolini P, Perrin M, Farah I, Magne JL, Guidicelli H. Management of symptomatic and asymptomatic popliteal venous aneurysms: a retrospective analysis of 25 patients and review of the literature. Vasc Surg. 2000;32(5):902-912.

6. Sessa C, Nicolini P, Perrin M, et al. Management of symptomatic and asymptomatic popliteal venous aneurysms (a retrospective analysis of 25 patients and review of the literature). J Vasc Surg. 2000;32 (5):902-912. doi:10.1067/mva.2000.110353

7. Galie N, Humbert M, Vachiery J-L, et al. ESC scientific document group. $2015 \mathrm{ESC} / \mathrm{ERS}$ guidelines for the diagnosis and treatment of pulmonary hypertension: the joint task force for the diagnosis and treatment of pulmonary hypertension of the European Society of Cardiology (ESC) and the European Respiratory Society (ERS): endorsed by: Association for European Paediatric and Congenital Cardiology (AEPC), International Society for Heart and Lung Transplantation (ISHLT). Eur Heart J. 2016;37(1):67-119. doi:10. 1093/eurheartj/ehv317

8. Konstantinides SV, Torbicki A, Agnelli G, et al. Task force for the diagnosis and management of acute pulmonary embolism of the European Society of Cardiology (ESC). 2014 ESC guidelines on the diagnosis and management of acute pulmonary embolism. Eur Heart J. 2014;35(43):3033a-3069k.
9. The EINSTEIN Investigators. Oral rivaroxaban for symptomatic venous thromboembolism. $N$ Engl J Med. 2010;363(26):2499-2510. doi:10.1056/NEJMoa1007903

10. Klok FA, van der Hulle T, den Exter PL, Lankeit M, Huisman MV, Konstantinides S. The post-PE syndrome: a new concept for chronic complications of pulmonary embolism. Blood Rev. 2014;28(6): 221-226. doi:10.1016/j.blre.2014.07.003

11. Condliffe R, Kiely DG, Gibbs JSR, et al. Improved outcomes in medically and surgically treated chronic thromboembolic pulmonary hypertension. Am J Respir Crit Care Med. 2008;177(10):1122-1127. doi:10.1164/rccm.200712-1841OC

12. Sugimura K, Fukumoto Y, Satoh K, et al. Percutaneous transluminal pulmonary angioplasty markedly improves pulmonary hemodynamics and long-term prognosis in patients with chronic thromboembolic pulmonary hypertension. Circ J. 2012;76(2):485-488. doi:10. 1253/circj.CJ-11-1217

13. Noppeney T, Kopp R, Pfister K, Schierling W, Noppeney J, Beatrix Cucuruz MD. Treatment of popliteal vein aneurysms. J Vasc Surg. 2019;7:535-542.

\section{Publish your work in this journal}

The International Medical Case Reports Journal is an international, peer-reviewed open-access journal publishing original case reports from all medical specialties. Previously unpublished medical posters are also accepted relating to any area of clinical or preclinical science. Submissions should not normally exceed 2,000 words or 4 published pages including figures, diagrams and references. The manuscript management system is completely online and includes a very quick and fair peer-review system, which is all easy to use. Visit http://www.dovepress.com/testimonials.php to read real quotes from published authors. 